\title{
Relationships Among Annual Revenue and Green Initiatives, Quality Management, and Organizational Performance
}

\author{
Yun-Chen Morgan, PhD \\ Southeastern Louisiana University, Hammond, Louisiana, United States \\ Lillian Y. Fok, PhD \\ Western Washington University, Bellingham, Washington, United States \\ Susan M. L. Zee, PhD \\ Southeastern Louisiana University, Hammond, Louisiana, United States \\ Contact: susan.zee@selu.edu
}

\begin{abstract}
Today's global awareness of environmental risks and the pressing needs to compete through efficiency have led to stronger initiatives in the green movement across industries. We examine organizations' annual revenue levels and their connections to organizational green orientation and impact, quality management programs, and employee perceptions of cultural practices and organizational performance. Results indicate high-revenue organizations use quality management tools more extensively with greater green impact and low-revenue organizations have a more informal and decentralized organizational culture.
\end{abstract}

Keywords: green movement; quality management; organizational culture

Date Submitted: February 4, 2019 | Date Published: April 8, 2020

Recommended Citation

Morgan, Y.-C., Fox, L. Y., \& Zee, S. M. L. (2020). Relationships among annual revenue and green initiatives, quality management, and organizational performance. International Journal of Applied Management and Technology, 19, 13-25. https://doi.org/10.5590/IJMAT.2020.19.1.02

\section{Introduction}

With the globalization of the economy and an increasingly competitive market environment, many organizations have turned to ways such as green movement and total quality management (TQM) to make their processes more efficient and effective and to improve their competitive advantage (Doszhanov \& Ahmad, 2015; Lagas, 2016; Paul et al., 2014; Yang, 2017). Depending on the size of the organizations, management of these strategic initiatives will be drastically different; therefore, organizational size, culture, green movement, and TQM will be the focus of this research.

Environmental preservation is one of the increasingly important challenges in 21st-century manufacturing. Today, many industrialized countries enjoy affluent products, food, energy, and so forth, but current 
governmental, corporate, and private efforts to overcome the negative environmental/energy impact have not been effective enough to solve the problem worldwide (Ahn, 2014). Along with resource and energy deficiency and the rise of ecofriendly products generated by consumer demand, the green movement has rapidly taken center stage in most companies' operations. The awareness of diminishing supply of natural resources is congruent with the belief that ecological balance may be at a critical disruption stage (Hayes, 1990).

Preservation issues have forced companies-small and large, domestic and international-in every industry to dig deeper into their strategies, practices, and goals to sustain operations and profitability.

Most green movement research focus on the topics of green manufacturing, sustainability, green marketing, or green consumers. Few, if any, discuss internalized characteristics and mechanisms that can influence the success of green initiatives and the implications on organizational performance. This study examines organizations' green orientation, employee perceptions of companies' commitment to greener practices, TQM programs, organizational culture, and performance. Specifically, we focus on organizational size in terms of annual revenue and explore the connections between annual revenue and the green movement within companies, which may lead to organizational success.

\section{Literature Review}

Recent climate events and reports constantly remind us the importance of corporate environmental sustainability and responsibility. Sustainability is commonly defined as the ability to meet the needs of the present generation without compromising the ability of future generations to meet their own needs (World Commission on Environment and Development, 1987). There has been increased interest in the green movement in academia. Most studies focus on green manufacturing (Deif, 2011; Ma et al., 2016; Sen et al., 2015; Sezen \& Cankaya, 2013), sustainability (Ahn, 2014; Lagas, 2016; Paul et al., 2014), green marketing (Maheshwari, 2014; Sujith, 2017; Yeow \& Yazdanifard, 2014), and consumer behavior toward green products (Doszhanov \& Ahmad, 2015; Sandu, 2014; Yang, 2017).

\section{The Green Movement and Sustainability}

More companies go green because of the realization that they can contribute to the preservation of our environment and increase profits at the same time. Businesses across industries are going green, including technology, petroleum, and various production industries. The term green manufacturing reflects the new manufacturing standard that employs various 'green'-more eco-efficient-strategies and techniques (Deif, 2011). Green strategies include companies' objectives and principles, while green techniques include technology and innovative methods.

The ability to grow and remain profitable is certainly a top priority for all domestic and international businesses. Companies all over the globe are under pressure from stakeholders to be eco-efficient (Klebnikoff, 1996). Cost saving and market opportunity potential come with the practice of green marketing. Green marketing incorporates a broad range of activities such as research and development, advertising, packaging, production process, as well as modifications of the aforementioned activities. Green marketing is not limited to adding a green theme to a company's brand. It is the overall efforts to eliminate marketing processes that are detrimental to the environment and the utilization of environmentally safe processes in all aspects of product marketing. While firms may have to invest more initially, the investment will pay off in the long run in increased sales and revenue, long-term growth and profitability, and positive corporate identity (Maheshwari, 2014).

Today's consumers are more conscious about the environment and pay more attention to firms, products, and processes and whether operations are being carried out in a socially responsible manner. The well-being of planet earth has become a critical issue so much so, it is influencing how products are developed, marketed, 
and disposed of. Most studies have focused on the general environmental behavior instead of consumer behavior specifically (Gan et al., 2008). Green consumers arose from the preference of green manufacturing and eco-friendly products (Sandu, 2014), and they are defined as someone who voluntarily engages in consumer practices that are regarded as environmentally friendly (Peattie, 2001). Green consumers typically support eco-friendly attitudes and purchase green products over standard alternatives. Inevitably, businesses who position themselves as sellers of eco-friendly or environmentally friendly products may enjoy more competitive advantage among these customers (Sujith, 2017).

Environmental sustainability has been defined as a management approach that involves developing strategies that sustain the environment and produce profits for the company (Maheshwari, 2014). It is the creation of products which minimizes the negative environmental impact while conserving natural resources. Hence, sustainability benefits business when they switch to greener manufacturing practice. These benefits include sales increase, expanding market share, energy cost savings, government incentives, higher workplace morale and sense of pride, and improved health and safety (Apple Rubber, 2016; Lagas, 2016).

Environmental issues and sustainability have become some of the most vital topics for management, strategic business, manufacturing, and product development decisions, as a result of hasty reduction of natural resources and concerns over corporate social responsibility (Sezen \& Cankaya, 2013). The shift to using materials that are more environmentally friendly has led to the development of lower cost products that ultimately do less damage to the environment (Paul et al., 2014). Yet there are misconceptions of going green, and that is, while going green convey the sense of ability and responsibility on converting outputs or recycling, sustainability takes it beyond the day to day duties to become part of a firm's strategy and its identity.

\section{Total Quality Management (TQM), Sustainability, and Green Initiatives}

Employee attitudes regarding green initiatives may be influenced by their perceptions toward TQM programs implemented in the workplace. Previous research which examined employee involvement (Rapp \& Eklund, 2002), human resource management and leadership (Daily \& Huang, 2001), commitment (Matta et al., 1996), and personality traits (Ahmad \& Schroeder, 2002) all expressed possible connections between perceptions and attitudes. How employees perceive the effectiveness of varying TQM tools employed in the workplace should have significant consequences on employees' attitudes about going green. In addition, recent research showed important underlying issues involving the depth or qualitative aspects of the organization's experience with quality management (QM) - a term referred to as QM maturity (Fok et al., 2000). Specifically, Fok, et al. reported the importance of distinguishing between the length of time an organization reported deploying quality management tools, and the quality of its implementation.

Being green positively impact organizations' competitive edge in many aspects, including research, manufacturing, marketing, and sustainability. Sustainable development is based on the perceived need to address environmental deterioration and to maintain vital functions for the well-being of all generations. It has been perceived as a new tool in company planning (Beatley \& Manning, 1998) and a fundamentally important concept which should influence all policy developments within a firm (Loffler, 1998). Zairi and Liburd (2001) defined sustainability development as the ability of an organization to adapt to change in the business environment to deploy best contemporary methods to achieve and further maintain superior performance. Their take on sustainability development implies competitiveness and an organization's competitiveness is partly dependent on their quality management practices. TQM represents the integrative approach in the pursuit of customer satisfaction (Chin et al., 2001) and overall success. Facing intense pressure from global competition, organizations realize the need to incorporate sustainable development and TQM to reach higher level of improvement and ultimate profitability (Hitchcock \& Willard, 2002; Jonker, 2000; McAdam \& Leonard, 2003). The idea of expansion of TQM to include sustainability, and the expansion being fueled by pressure to ensure long-term survival or growth surrounded by the emphasis of globalization is thus born (Dervitsiotis, 2001; Wilkinson et al., 2001; Zairi, 2002) 
Morgan et al., 2020

\section{Organizational Culture}

Organizational culture often is an invaluable tool used to implement company strategies. When green movement inevitably becomes a part of organizational strategy, the culture that binds members of the organization together also impact the level of success on green initiatives. As society gets on board with the preservation of our environment, companies risk developing a poor image if they neglect in their part in implementing the needed change internally. Companies incorporating these initiatives within part of their corporate culture could become the leaders in the green movement and reach higher level of sustainability and profitability (Acharya et al., 2014).

In this research, we posit that organizational culture may impact employee perceptions of the green movement and its importance to the organization, as well as impacting individual employees personally. In addition, corporate culture may influence employee perceptions of performance outcomes. We theorize that as organizations become greener, organizational culture will become more employee- and customer-centered, and employees may become more empowered. In turn, supportive organizational culture towards the green movement will lead to higher performance, perhaps in part through employees who are more supportive of the green movement.

\section{Organization Size}

Size is highly relevant to organizational strategy and structure, as mentioned in the literature of "Differences Between Strategic Planning at Small Versus Large Firms” (Boundless, 2016). In an early research, Child (1972) highlighted the importance of strategic choice by organizational decision makers and its impact upon factors including organizational size and market focus. Other research has previously examined whether organizations of different size and market focus may differ on several variables related to the green movement and Quality Management in Jamaica and in the United States (Zee et al., 2011). In other research, company size impacts its focus points, challenges and approaches in quality management strategies (Ahire \& Golhar, 1996; Roberts, 2013). Studies can be found looking specifically into firm size versus implementation successes of quality management programs. For example, studies by Kober et al. (2012), Assarlind and Gremyr (2014), as well as Melao and Guia (2015) all reinforced the differences in ability to successfully implement quality management programs between large firms and small firms. Finally, Cho (1994) and Isa et al. (2016) investigated the factors affecting successful implementation of TQM in large versus small organizations in the United States and in Malaysia, respectively. In turn, these choices ultimately impact organizational effectiveness (see especially Beckman, 2006; Kreitner \& Kinicki, 2007).

\section{The Gaps in the Literature}

Although previous literature has explored the impact of TQM and organizational culture on organizational performance and the impact of green movement on organizational performance, few studies have been conducted comparing organizations of different sizes. Drawing from the previous literature, in this study, we propose that organization size is a critical factor impacting the extent of green movement and Quality Management organizations embraced in the United States which leads to differing culture and organizational outcomes.

\section{Research Question}

In this study, we examine issues regarding the impact of size in terms of revenue to consider organizational culture, employee perceptions of organizational commitment to the green movement and QM maturity of the organization. The organization itself will be seen as doing better and the impact of the Green Movement will be perceived as favorable where there is a higher level of perceived commitment to the green movement and 
where more mature QM systems are in place (Chin et al., 2001; Zee et al., 2011). Small and large organizations use different strategies to create competitiveness and have different availability of resources, and therefore are expected to have different levels of organizational green orientation, QM maturity, organizational culture, and report differing impacts of the green movement. Hence we have the following research question.

Research Question: Small and large organizations in terms of annual revenue will have different levels of organizational green orientation, organizational culture, QM maturity, organizational performance, and report differing impacts of the green movement.

\section{Methodology}

\section{Subjects of the Study}

Subjects in the sample were approximately 229 full-time employees from a wide variety of industries in a major metropolitan city in the Deep South in the United States. The subjects were roughly $54.8 \%$ male and $45.2 \%$ female with an average age of 41.49 years. Among these 229 subjects, they have an average of 19.91 years of working experience, including 9.46 years in management positions. There are approximately nine categories of industries in our survey instrument. The three largest percentages of the subjects work in retail, health care, and manufacturing industries with $18.4 \%, 14.9 \%$, and $14 \%$, respectively. The results are shown in Table 1.

Table 1. Frequencies by Industry Type and Annual Revenue of Organizations

\begin{tabular}{lcc}
\hline \multicolumn{1}{c}{ Demographic } & $\boldsymbol{n}$ & $\mathbf{\%}$ \\
\hline Industry & 32 & 14.0 \\
Manufacturing & 15 & 6.6 \\
Financial Services & 42 & 18.4 \\
Retail & 9 & 3.9 \\
Utilities & 6 & 2.6 \\
High Technology & 18 & 7.9 \\
Education & 34 & 14.9 \\
Health Care & 5 & 2.2 \\
Government & 67 & 29.4 \\
Other & 228 & 100.0 \\
Total & & \\
Revenue & 59 & 29.8 \\
$>$ \$1 Billion & 8 & 4.0 \\
\$501-1,000 Million & 8 & 4.0 \\
\$251-500 Million & 11 & 5.6 \\
\$101-250 Million & 12 & 6.1 \\
\$51-100 Million & 19 & 9.6 \\
\$25-50 Million & 81 & 40.9 \\
$<\$ 25$ Million & 198 & 100.0 \\
Total & &
\end{tabular}


Approximately $25.8 \%$ of the subjects are employed in a company with $>\$ 1$ billion in annual revenue, $3.5 \%$ with $\$ 501$ million to $\$ 1$ billion, 3.5\% with $\$ 251-\$ 500$ million, $4.8 \%$ with $\$ 101-\$ 250$ million, $5.2 \%$ with $\$ 51-$ $\$ 100$ million, $8.3 \%$ with $\$ 25-\$ 50$ million, and $35.4 \%$ are employed in a company with $<\$ 25$ million in annual revenue. Subjects responded to a survey which asked about their perceptions and experiences about the green movement, quality management, and organizational culture in their own firms. In this study, we will concentrate on the relationships among organizational size in terms of annual revenue, commitment to the green movement, quality management, organizational performance, and impacts of organizational culture.

\section{Instruments}

\section{Organizational Green Orientation}

Based on previous research (Li et al., 2009), we measured the Organizational Green Movement by using the survey which provides 21 organizational green initiatives question items. The factor Green Orientation is a count of the total numbers of green initiatives implemented in an organization.

\section{Quality Management (QM) Maturity}

In this study, QM maturity refers, in a qualitative sense, to the degree of QM implementation in an organization. We suggest and previous research has shown (Ahire \& Golhar, 1996; Flynn et al., 1994; Fok et al., 2000, 2001; Patti et al., 2001; Saraph et al., 1989) that it can be measured by examining the perceived use of QM programs. These ideas assume that if an organization has more completely followed the QM philosophy, QM programs should be used throughout the organization and in various functional areas, rather than in isolation. Moreover, if quality is indeed everyone's job, where QM is more fully in place, employees should be aware of the various TQM tools and techniques which are in use. If an organization, on the other hand, has very little or no experience with QM, the opposite is expected to occur. In earlier research (Fok et al., 2000; Fok et al., 2001; Patti et al., 2001), we began the process of developing a measure of QM maturity. The instrument we developed dealt with perceived program use and asked respondents whether certain programs were in use in the organization, with a range from not used to high usage.

In this study, consistent with our earlier research, the QM maturity instrument was used to gauge QM maturity. We conducted a factor analysis to identify the underlying dimensionality. Two factors emerged from the Usage items. The first factor appeared to include all the traditional quality management programs and was termed Basic Quality Improvement Tools. The second factor was termed Advanced Quality Improvement Tools which includes programs like Six Sigma programs and Black Belt training. $68.27 \%$ of the variance was explained by these two factors. Table 2 below provides the items and shows the results of our factor analysis.

\section{Organizational Culture}

Based on previous research (Fok et al., 2000; Fok et al., 2001; Harman et al., 2009), we measure the Organizational Culture by constructing a series of paired opposite items which asked whether the organization's climate should be described as open vs. closed, soft vs. tough, competitive vs. collaborative, and the like. Table 3 provides the items and shows the results of our factor analysis. We obtained a three-factor solution in case of the Organizational Culture items and have labeled Factor 1 as TQM Culture, Factor 2 as People-Centered Culture, and Factor 3 as Personal Culture. 56.56\% of the variance was explained by these three factors. 
Table 2. Factor Analysis on Quality Programs Usage Items

\begin{tabular}{lcc}
\hline & \multicolumn{2}{c}{ Component } \\
\cline { 2 - 3 } & $\mathbf{1}$ & $\mathbf{2}$ \\
\hline Rotated component matrix & .643 & .188 \\
Quality management program & .714 & .154 \\
Employee suggestion channels & .830 & .039 \\
Employee quality training programs & .756 & .157 \\
Quality improvement seminars & .223 & .929 \\
Six Sigma programs & .120 & .949 \\
Black Belt training & & \\
& & \\
Rotation sums of squared loadings & & 1.848 \\
Total & 2.248 & 30.807 \\
\% of Variance & 37.464 & 68.271 \\
Cumulative \% & 37.464 & \\
\hline
\end{tabular}

Table 3. Factor Analysis on Quality Programs Usage Items

\begin{tabular}{lccc}
\hline & \multicolumn{3}{c}{ Component } \\
\cline { 2 - 4 } & $\mathbf{1}$ & $\mathbf{2}$ & $\mathbf{3}$ \\
\hline Rotated component matrix & & & .137 \\
Open & .728 & .191 & .132 \\
Soft & .213 & .643 & -.326 \\
Informal & -.200 & .658 & -.013 \\
Team-oriented & .717 & -.179 & .952 \\
Personal & .037 & .032 & .070 \\
Decentralized & -.171 & .685 & .007 \\
Participative & .729 & .037 & .031 \\
Proactive & .591 & -.206 & \\
& & & 1.056 \\
Rotation sums of squared loadings & Total variance explained & & 13.194 \\
Total & & 1.429 & 56.563 \\
\% of Variance & 2.040 & 17.863 & \\
Cumulative \% & 25.505 & 43.368 & \\
\hline
\end{tabular}

\section{Organizational Performance}

The Organizational Performance items were primarily adapted from the Malcolm Baldridge National Quality Award outcome assessment measures. The Baldridge Awards are designed to identify organizations which are performing in an exceptional manner and include criteria for identifying excellence. We used the Baldridge criteria in the form of a scale which asks respondents to provide perceptions about their organizations along Baldridge lines. The resulting scale has been used and reported in previous work (Fok et al., 200o; Fok et al., 2001; Hartman et al., 2009). The instrument included are items such as "Overall, my company is performing well," "Overall, morale in my company is high," "Overall, I am satisfied with the use of technology in my 
Morgan et al., 2020

company," and the like. Factor analysis in this study indicated that one factor was present. The results showed that $56.01 \%$ of the variance was explained by the factor and we named the factor as Organizational Success.

\section{Impact of Green Movement}

The instruments included are items such as Provide better products, Provide better services, Have better relationship with customers, Have better relationship with suppliers, Have better reputation, Provide better working environment, Increase profits, Reduce costs, and Improve productivity. Factor analysis produced a single-factor solution and we named it Impact of Green Movement. 70.36\% of the variance was explained by this factor.

\section{Revenue Size}

In this research, we extend the respondents to report the approximate annual revenue in their organizations. Those who reported with less than \$25 million annual revenue are grouped into the small revenue group and those who reported with over $\$ 1,000$ million annual revenue are grouped into the large revenue group. While those with between $\$ 25$ million and $\$ 1,000$ million annual revenues are dropped from the analysis.

\section{Results}

Our research question suggested that small revenue (less than \$25 million annual revenue) and large revenue (over \$1,00o million annual revenue) organizations would have different levels of organizational green orientation, organizational culture, QM maturity, organizational performance, and impact of the green movement. As shown in Table 4, the multivariate analysis of variance results are significant with $p$ value of .0oo, which implies that small revenue organizations were significantly different from large revenue organizations, and that respondents reported different levels of organizational culture, QM maturity, and impact of the green movement. Among the eight factors (ss shown in Table 5), we found that Impact of Green Movement is significant at the level of .001. The mean factor score of large revenue companies (0.379) is larger than that of small size companies $(-0.163)$. The results suggest that large revenue organizations have higher levels of impact of the green movement than small revenue organizations. Both Use of Basic Quality Improvement Tools and Use of Advanced Quality Improvement Tools are statistically significant at the levels of .005 and .001, respectively. For Use of Basic Quality Improvement Tools, the mean factor score of large revenue companies (0.255) is greater than that of small revenue companies (-0.238). For Use of Advanced Quality Improvement Tools, the mean factor score of large revenue companies (0.408) is greater than that of small revenue companies ( -0.183$)$. The results imply that large revenue organizations have higher levels of usage of both traditional TQM tools and advanced TQM tools than small revenue organizations. Both PeopleCentered Culture and Personal Culture are significant at the levels of .005 and .013, respectively. For PeopleCentered Culture, the mean factor score of small revenue organizations (0.275) is greater than that of large revenue organizations (-0.203). For Personal Culture, the mean factor score of small revenue companies (0.120) is greater than that of large revenue companies (-0.330). The results suggest that small revenue companies are more informal, more decentralized, and more personal than large revenue companies. 
Table 4. Summary of Multivariate Analysis of Variance Results: Revenue/Sales Size

\begin{tabular}{lccccc}
\hline \multicolumn{1}{c}{ Effect } & Value & $\boldsymbol{F}^{\mathbf{a}}$ & Hypothesis $\boldsymbol{d} \boldsymbol{f}$ & Error $\boldsymbol{d} \boldsymbol{f}$ & Sig. \\
\hline Intercept & & & & & \\
$\quad$ Pillai's trace & .886 & 124.359 & 8.000 & 128.000 & .000 \\
Wilks' $\lambda$ & .114 & 124.359 & 8.000 & 128.000 & .000 \\
Hotelling's trace & 7.772 & 124.359 & 8.000 & 128.000 & .000 \\
$\quad$ Roy's largest root & 7.772 & 124.359 & 8.000 & 128.000 & .000 \\
Sales & & & & & \\
$\quad$ Pillai's trace & .224 & 4.621 & 8.000 & 128.000 & .000 \\
Wilks' $\lambda$ & .776 & 4.621 & 8.000 & 128.000 & .000 \\
Hotelling's trace & .289 & 4.621 & 8.000 & 128.000 & .000 \\
$\quad$ Roy's largest root & .289 & 4.621 & 8.000 & 128.000 & .000 \\
\hline
\end{tabular}

Note. $R^{2}=.013$ (adjusted $R^{2}=.003$ ).

Table 5. Multivariate Analysis of Variance: Significant Dependent Variables

\begin{tabular}{lc}
\hline \multicolumn{1}{c}{ Dependent variable } & Significance \\
\hline Green orientation & .097 \\
Impact of green movement & $.001^{*}$ \\
TQM culture & .721 \\
People-centered culture & $.005^{*}$ \\
Personal culture & $.013^{*}$ \\
Basic TQM tools & $.005^{*}$ \\
Advanced TQM tools & $.001^{*}$ \\
Organizational performance & .858 \\
\hline
\end{tabular}

Note. TQM = total quality management.

${ }^{*} p<.05$ for the $F$ test.

\section{Discussions and Conclusions}

Engaging in activities which increase profit while still being socially responsible is understandably one of the top goals of every company. Though within the multifaceted operations of a business and complexity surrounding the aspects of business decisions, we understand some facets must be prioritized and other must be sacrificed to some extent. Case in point, not all consumers are willing to pay for greener products which may cost more even though they are efficient in the long run. In the quest of being environmentally responsible, profitability may suffer, and with the effort to please green oriented customers, production value may decline.

How much adjustments to the internal system dictates the success or failure of certain implementations within the company. These adjustments are decided by how much organizational resources a company can garner. To a certain extent, the ability to mobilize resources is affected by the financial wealth of the company. In this research, we investigated whether companies with large annual revenue report differing perceptions of the company's impact on the environment compared to companies with small annual revenue. Results showed that participants from larger revenue companies perceive stronger impact. This is not unexpected, as wealthier organizations typically have more resources to secure more impactful outcomes. In addition, larger organizations also have more means to advertise organizational impact and success internally. These 
advertisement increase awareness, and therefore influence perceptions of success. The lack of internal promotion and devoted resources of the green impact may explain the difference in the reported results.

Regarding quality management maturity, where annual revenue was considered, results indicated that larger revenue organizations report higher usage of traditional TQM tools and advanced TQM tools compared to smaller revenue organizations. This can also be explained by the availability of resources. Implementing TQM tools can be rather costly, and affordability may be a factor for smaller revenue companies. Our findings further suggested that smaller revenue companies tend to have more informal, personable, and decentralized culture. This could be the result of a natural progression of span of control, as when companies grow larger in size, it often leads to more organizational levels. When more organizational levels are created, the distance between human interactions increase, resulting in the perception of a more formal and less personal work space.

\section{Limitations and Future Study}

There are several limitations of this study. Firstly, the geographic location of this study is a metropolitan city in the Deep South of the United States. The southern states have unique cultures which could affect employees' perception of the impact of green movement and could influence organizations' adoption of strategic programs, like green movement and quality management tools. Future study should include respondents from various geographic locations in the United States, as well as different countries. Secondly, the data collection is done through self-reported survey instruments. Because a single respondent is used from each organization, the results could be subject to respondent's personal bias. Multiple respondents could be used within each organization to validate the responses to eliminate possible biases. Finally, Green Movement and Quality Maturity of an organization are measured by the number of adopted green initiatives and the number of quality improvement tools. In addition to the quantity of tools used, we could measure the extent of use as well.

\section{Conclusion}

Going green is a movement, and with every movement comes opportunities. When businesses are able to capitalize on the movement and modify aspects of their operations to be greener, they benefit in the forms of increased sales and expanded market shares. Eco-friendly products can also provide consumers with a sense of responsibility and positive impact through purchases (Kangovou, 2017). The pressure to reverse the negative consequences on our environment with our growing industrial ways of life is mounting and we must find ways to reduce our carbon footprint. This study acknowledges the effort and movement to reduce environmentally harmful processes and the factors which influence the movement. With this understanding, businesses may improve not only their operations and workers' skillsets, they may also increase the morale and motivation, as well as health and safety benefits of employees.

\section{References}

Acharya, S. G., Vadher, J. A., \& Acharya, G. D. (2014). A review on evaluating green manufacturing for sustainable development in foundry industries. International Journal of Emerging Technology and Advanced Engineering, 4, 232-237.

Ahire, S. L., \& Golhar, D. Y. (1996). Quality management in large versus small firms:An empirical investigation. Journal of Small Business Management, 34, 1-13.

Ahmad, S., \& Schroeder, R. G. (2002). The importance of recruitment and selection process for sustainability of total quality management. International Journal of Quality \& Reliability Management, 19, 540550. 
Ahn, S. H. (2014). An evaluation of green manufacturing technologies based on research databases. International Journal of Precision Engineering and Manufacturing Green Technology, 1, 5-9.

Apple Rubber. (2016). 5 Important reasons to embrace sustainable manufacturing [Blog]. https://www.applerubber.com/blog/5-important-reasons-to-embrace-sustainable-manufacturing

Assarlind M., \& Gremyr, I. (2014). Critical factors for quality management initiatives in small- and mediumsized enterprises. Total Quality Management \& Business Excellence, 25, 397-411.

Beatley, T., \& Manning, K. (1998). The ecology of place: planning for environment, economy and community. Island Press.

Beckman C. M. (2006). The influence of founding team company affiliations on firm behavior. Academy of Management Journal, 49, 741-758.

Boundless. (2016). Differences between strategic planning at small versus large firms. https://www.boundless.com/management/textbooks/boundless-management-textbook/strategicmanagement-12/strategic-management-86/differences-between-strategic-planning-at-small-versuslarge-firms-418-1407

Child, J. (1972). Organization structure, environment and performance: The role of strategic choice. Sociology: The Journal of the British Sociological Association, 6, 1-22.

Chin, K. S., Pun, K. F., \& Hua, H. M. (2001). Consolidation of China's quality transformation efforts: A review. International Journal of Quality \& Reliability Management, 18, 836-853.

Cho, K. (1994). Impact of total quality management (TQM) on organizational performance in the U.S.: An empirical investigation of critical success factors. ETD collection for University of NebraskaLincoln. http://digitalcommons.unl.edu/dissertations/AAI9425277

Daily, B. F., \& Huang, S. (2001). Achieving sustainability through attention to human resource factors in environmental management. International Journal of Operations\& Production Management, 21, 1539-1552.

Deif, A. M. (2011). A system model for green manufacturing. Journal of Cleaner Production, 19, 1553-1559.

Dervitsiotis, K. (2001). Emerging elements of a world view for sustainable quality. Total Quality Management, 12, 817-824.

Doszhanov, A., \& Ahmad, Z. A. (2015). Customers' intention to use green products: The impact of green brand dimensions and green perceived value. https://www.researchgate.net/publication/281733955

Flynn, B. B., Schroeder, R. G., \& Sakakibara, S. (1994). A framework for quality management research and an associated measurement instrument. Journal of Operations Management, 11, 339-366.

Fok, L. Y., Fok, W. M., \& Hartman, S. J. (2001). Exploring the relationship between total quality management and information systems development. Information \& Management, 38, 355-371.

Fok, L. Y., Hartman, S. J., Patti, A. L., \& Razek, J. R. (2000). The relationship between equity sensitivity, growth need strength, organizational citizenship behavior, and perceived outcomes in the quality environment: A study of accounting professionals. Journal of Social Behavior and Personality, 15, 99-120.

Gan, C., Wee, H. Y., Ozanne, L., \& Kao, T (2008). Consumers' purchasing behavior towards green products in New Zealand. Innovative Marketing, 4, 93-102.

Hartman, S. J., Fok, L. Y., \& Zee, S. M. (2009). Linkage among employee perceptions of organizational commitment to the green movement and organizational culture, and their perceived impacts upon outcomes. Journal of Organizational Culture, Communications and Conflict, 13, 27-44. 
Hayes, D. (1990). The green decade. The Amicus Journal, 12, 24-29.

Hitchcock, D., \& Willard, M. (2002). Sustainability: enlarging quality's mission. Quality Progress, 35, 43-47.

Isa, M. R., Zaroog, O. S., \& Raju, S. (2016). Survey on total quality management in small and medium manufacturing industries in Shah Alam. International Journal of Science and Research, 5, 848-853.

Jonker, J. (2000). Organizations as responsible contributors to society: Linking quality, sustainability and accountability. Total Quality Management, 11, 741-746.

Kangovou. (2017). The importance of eco-friendly products. https://www.kangovou.com/the-importance-ofeco-friendly-products

Klebnikoff, S. D. (1996). Eco-efficient leadership: The road to new business opportunities. Proceedings of the Asian Productivity Organization World Conference on Green Productivity (pp. 491-502), Manila, Philippines.

Kober, R., Subraamanniam, T., \& Watson, J. (2012). The impact of total quality management adoption on small and medium enterprises' financial performance. Accounting \& Finance, 52, 421-438.

Kreitner, R., \& Kinicki, A. (2007). Organizational behavior. McGraw-Hill.

Lagas, B. (2016). Five benefits of sustainability and green manufacturing. Quality Digest. https://www.qualitydigest.com/inside/customer-care-column/five-benefits-sustainability-andgreen-manufacturing-101816.html

Li, J., Hartman, S. J., \& Zee, S. M. L. (2009). A study of green movement perceptions and behavioral intentions. International Journal of Sustainable Economy, 1, 133-143.

Loffler, P. (1998). Sustainable development in Europe. A Cause for Regional Environment, 8, 113-120.

Ma, C., Liu, X., Zhang, H., \& Wu, Y. (2016). A green production strategies for carbon sensitive products with a carbon cap policy. Advances in Production Engineering and Management, 11, 216-226.

Maheshwari, S. P. (2014). Awareness of green marketing and its influence on buying behavior of consumers: Special reference to Madhya Pradesh, India. AIMA Journal of Management \& Research, 8, 497-505.

Matta, K., Davis, J., Mayer, R., \& Conlon, E. (1996). Research questions on the implementation of total quality management. Total Quality Management, 7, 39-49.

McAdam, R., \& Leonard, D. (2003). Corporate social responsibility in a total quality management context: Opportunities for sustainable growth. Corporate Goverance, 3, 36-45.

Melao, N. F., \& Guia S. M. (2015). Exploring the impacts of ISO 9001 on small- and medium-sized social service institutions: A multiple case study. Total Quality Management \& Business Excellence, 26, 312-326.

Patti, A. L., Hartman, S. J., \& Fok, L. Y. (2001). Investigating organizational quality management maturity: An investment validation study. International Journal of Quality \& Reliability Management, 18, 882899.

Paul, I. D., Bhole, G. P., \& Chaudhari, J. R. (2014). A review on green manufacturing: Its importance, methodology and its application. Procedia Materials Science, 6, 1644-1649.

Peattie, K. (2001). Towards sustainability: The third age of green marketing. The Marketing Review, 2, 129146.

Rapp, C., \& Eklund, J. (2002). Sustainable development of improvement activities -the long-term operation of a suggestion scheme in a Swedish company. Total Quality Management, 13, 945-969. 
Roberts, M. (2013). Large versus small business quality management strategies. http://blog.lnsresearch.com/bid/179410/large-versus-small-business-quality-managementstrategies-data

Sandu, R. (2014). Green: Marketing, products, and consumers. SEA-Practical Application of Science, 2, 555562.

Saraph, J. V., Benson, G. P., \& Schroeder, R. G. (1989). An instrument for measuring the critical factors of quality management. Decision Sciences, 20, 810-829.

Sen, P. K., Bohidar, S. K., Shrivas, Y., Sharma, C., \& Modi, V. (2015). Study on innovation, research and recent development in technology for green manufacturing. International Journal of Mechanical Engineering and Robotics Research, 4, 185-194.

Sezen, B., \& Cankaya, S. Y. (2013). Effects of green manufacturing and eco-innovation on sustainability performance. Procedia-Social and Behavioral Sciences, 99, 154-163.

Sujith, T. S. (2017). Awareness of green marketing and its influence on buying behavior of consumers in Kerala. International Journal of Scientific Research and Management, 5, 43.

Wilkinson, A., Hill, M., \& Gollan, P. (2001). The sustainability debate. International Journal of Operations \& Production Management, 21, 1492-1502.

World Commission on Environment and Development. (1987). Report: Our common future. https://sustainabledevelopment.un.org/content/documents/5987our-common-future.pdf

Yang, Y. C. (2017). Consumer behavior towards green products. Journal of Economics, Business and Management, 5, 160-167.

Yeow, K. Y., \& Yazdanifard, R. (2014). The concept of green marketing and green product development on consumer buying approach. Global Journal of Commerce \& Management Perspective, 3, 33-38.

Zairi, M. (2002). Beyond TQM implementation: The new paradigm of TQM Sustainability. Total Quality Management, 13, 1161-1172.

Zairi, M., \& Liburd, I. M. (2001). TQM sustainability: A roadmap for creating competitive advantage. In Integrated Management, Proceedings of the 6th International Conference on ISO 9ooo and TQM. Paisely, Ayr, Scotland, April 17-19, Baptist University Press, Hong Kong (pp. 452-461).

Zee, S. M., Fok, L. Y., \& Harman, S. J. (2011). Exploring the relationships between organizational size and market focus and commitment to the green movement and impacts of organizational culture: A comparative study of Jamaica and the United States. International Journal of Business and Social Science, 2, 19-34.

\section{IJAMT}

The International Journal of Applied Management and Technology (IJAMT), sponsored by Walden University's College of Management and Technology, is a peer-reviewed, online journal that addresses contemporary national and international issues related to management and technology. 